\title{
Yağışların Trend Analizi
}

\author{
Hüseyin Yıldırım DALKILIÇ ${ }^{* *}$
}

Erzincan Binali Yıldırım Üniversitesi Müh. Fakültesi İnşaat Müh. Böl., Yalnızbağ Yerleşkesi, Erzincan

Geliş / Received: 5.07.2019, Kabul / Accepted: 15.12.2019

$\ddot{\mathbf{O z}}$

Bu çalışmada Gümüşhane, Erzincan, Bayburt gibi iklimsel olarak birbirine yakın olan bölgeler çalışma alanı olarak seçilmiştir. Son zamanlarda yoğun su kullanımının artması ve bunun beraberinde su kaynaklarının sınırlı olması, kaynakların optimum şekilde kullanılması gerektiğini ortaya koymuştur. Yağış yapısının birbirine paralel olduğu bu şehirlerde 1978-2018 yılları arasındaki 3 istasyondan alınmış veriler ile bölgedeki yağış trendlerinin tespiti amaçlanmıştır. Trend varlığını belirlemede Şen eğilim testi, Spearman Rho, Mann-Kendall ve Mevsimsel Mann-Kendall testleri kullanılmıştır. Bu testler sonucunda yaz döneminde belirli aylarda yağışlarda azalış, kış döneminde belirli aylarda ise yağışlarda artış olduğu görülmüştür.

Anahtar Kelimeler: Yağış Trend Analizi, Şen Eğilim Testi, Spearman Rho, Mann-Kendall, Mevsimsel MannKendall

\section{Trend Analysis of Precipitation}

\begin{abstract}
In this study, Gümüşhane, Erzincan and Bayburt, which have nearly same climatic conditions, were selected as case study area. In recent years, increasing the intensive water usage and limited water resources necessitated that water resources had to be used in optimum way. In this cities, which have similar precipitaiton pattern, trend analysis was aimed by using the precipitaiton data from 3 meteorological stations between the years 19782018. Şen Trend Test, Spearman Rho Test, Mann-Kendall Test and Seasonal Mann-Kendall Test were used to determine the trend of precipitaitons in these stations. As a result of these tests, it has been founded that precipitation decreases in certain months in summer and increases in in certain months in winter.
\end{abstract}

Keywords: Precipitation Trend Analysis, Şen Trend Test, Spearman Rho Test, Mann-Kendall Test, Seasonal Mann-Kendall Test 


\section{Giriş}

Dünya nüfusunun artması, sanayileşme, tarımsal ürünleri arttırma çabası, iklim değişiklikleri, ormanların zarar görmesi gibi pek çok etken çevre ve toplumu tehdit eden boyutlara taşımaktadır. Bunun yanında var olan su kaynaklarımız her geçen gün azalmaktadır. Türkiye Ulusal İklim Değişikliği Belgeselinde (2010) yapılan çalışmalarda; çalışmaların arttırılması, sonuçların tartışılması şeklinde bir strateji belirtilmiştir. Sanayi devriminin ilk yıllarından itibaren sanayileşme ile birlikte atmosferde sera gazlarının etkileri de artmaktadır. Bununla birlikte atmosfer 1sıy geçirip tutunca yer küre isınmaya başlayacak ve her geçen y1l iklim değişiklikleri gözle görülebilir derecede meydana gelecektir. İklim değişikliği; sıcaklığın yükselmesi, deniz seviyesinin yükselmesi, yağış̧ değişimi, kuraklık ve sel gibi istemediğimiz olayları beraberinde getirmektedir. $\mathrm{Bu}$ olayların çözümünde önemli olan tatlı su kaynaklarımızdan yağışların, akarsuların, göllerin ve yer altı su kaynaklarının planlamasının ve korunmasının büyük ölçüde sağlanabilmesidir. Planlamanın önemli noktalarından biri iste geçmişteki trendlerin sebep olduğu durumları görüp yorumlayabilmek ve ya gelecekteki trendlerin belirlenmesidir. Örneğin; bir sel felaketinin yaşanmaması için; mevcut yılların trendinde bir artış görünüyorsa gerekli tedbirler alınarak felaketlerin yaşanmasını önlemek muhtemeldir. Dünya'da ve Türkiye'de yağış, nem, buharlaşma, kuraklık gibi birçok meteorolojik alanda trend analizi çalışmaları yapılmıştır. (Ay ve Kişi ,2017) (Aydın ve Toplaoğlu , 2010)

Partal ve Kahya (2006), Türkiye genelinde Sen testi ve Mann-Kendall metotları ile 96 noktadaki yağış ölçüm verilerini kullanarak yıllık ortalama ve aylık yağış miktarlarında meydana gelen trendleri incelemiştir. Çalışma bulgularında özellikle 14 istasyonda Ocak ayındaki yağışın azalış trendi dikkat çekmektedir. Mekis and Vincent (2011), Kanada'da kış aylarındaki trendi araştırmıştır. $\mathrm{Bu}$ araştırmada 60 adet meteoroloji gözlem istasyonuna ait veriler kullanılarak MannKendall testi uygulanmıştır. Yapılan çalışmada 25 istasyonda artan trendin olduğunu görülmüştür. Gönençgil ve İçel (2010), Türkiye'nin Doğu Akdeniz bölgesinde 11 meteoroloji ölçüm istasyonuna ait verileri kullanmıştır. 1975-2006 yıllarındaki verilerden yararlanarak tek yönlü varyans analizi ile yıllık ve mevsimsel trendleri ortaya koymuştur. Çalışma sonucunda yağışlı gün sayısının ve yağış miktarının azaldığını, azalmanın ise ilkbahar kış mevsimlerinde daha gözle görülebilir olduğunu söylemiştir. Karpouzos vd.(2010), Yunanistan Pieria'daki 1974-2007 yıllarına ait verilerle aylık, yıllık, mevsimsel olarak trendleri ortaya koymuştur. Özellikle bahar aylarındaki yağış miktarında önemli düşüşler görülmüştür. Eğilimin ortaya çıkmasında Şen testi ve Mann-Kendall metotları trende imkân sağlamıştır. Bahadır (2011) Türkiye'nin Güneydoğu Anadolu bölgesinde sicaklık ve yağış trendi için ARIMA modelini kullanmıştır. Çalışma sonucunda 1992 yılında yaşanan soğuk havanın ardından sıcaklıkta sürekli olarak bir artışın olduğu gözlemlenmiştir. Bahadır(2011) yaptığı başka bir çalışmada Kızılırmak nehri ve havzasının iklim değişikliklerinden etkilenip etkilenmediğine dair bir araştırma yapmıştır. Bu araştırmada sıcaklıkla akım arasında ters bir ilişki söz konusuyken, yağışla akım arasında pozitif bir ilişkinin varlığından söz etmiştir. Aynı zamanda sıcaklık değerlerinde artış gözlemlenirken yağış ve akım değerlerinde ciddi oranda azalış meydana gelmektedir. Altın(2012), Orta Anadolu bölgesinde 1975- 
2007 yılları arasında 33 istasyona ait yağış ve sicaklık verilerini kullanarak trend analizi yapmıştır. Yapıla analizde Mann-Kendall testini kullanmış olup; yağışın kış ve ilkbahar aylarında azaldığını, yaz ve sonbahar aylarında ise artma eğiliminde olduğu gözlemlenmiştir. Huang vd.(2013), Çin'in Jiangxi şehrindeki yağış eğilimini belirlemek için Mann-Kendall testini uygulanmıştır. 1960-2008 y1llarını kapsayan verilerde çalışma sonucunda yağış trendinde farklı eğilimler belirlenmiştir. Adarsh ve Janga Reddy(2015), Hindistan'da 4 farkl1 meteoroloji gözlem istasyonlarına ait verilerle Mann-Kendall ve Şen testi metotlarını kullanarak yapılan analizlerde 3 bölgede artan diğer bölgede ise azalan bir eğilim olduğu tespit edilmiştir.
Yapılan bu çalışmada konumları birbirine yakın, ikisi Karadeniz bölgesi diğeri ise Doğu Anadolu bölgesinde yer alan üç ilin (Gümüşhane, Bayburt, Erzincan) 40 yıllık meteorolojik yağış verilerinde gözlenen eğilimler trend testleri uygulanarak araştırılmaya çalışılmıştır. Kullanılan trend yöntemlerinin birbirleri ile karşılaştırılması yapılmıştır. Anlamlı bir trendin varlığı ortaya koyulup bulgulara ait yorumlamalar yapılmıştır. (Bayazıt vd. ,2002) (Bacanlı ve Tanrıkulu, 2017)

\section{2. Çalışma Alanı}

$\mathrm{Bu}$ çalışmada 17089-Bayburt, 17094Erzincan, 17088-Gümüşhane istasyonlarına ait meteorolojik veriler kullanılmıştır. Tablo 1'de görüldüğü gibi enlem boylam ölçümleri üç ilinde birbirine paralellik göstermektedir.

Tablo 2.1 Meteoroloji gözlem istasyonlarına ait bilgiler (Meteoroloji 2012)

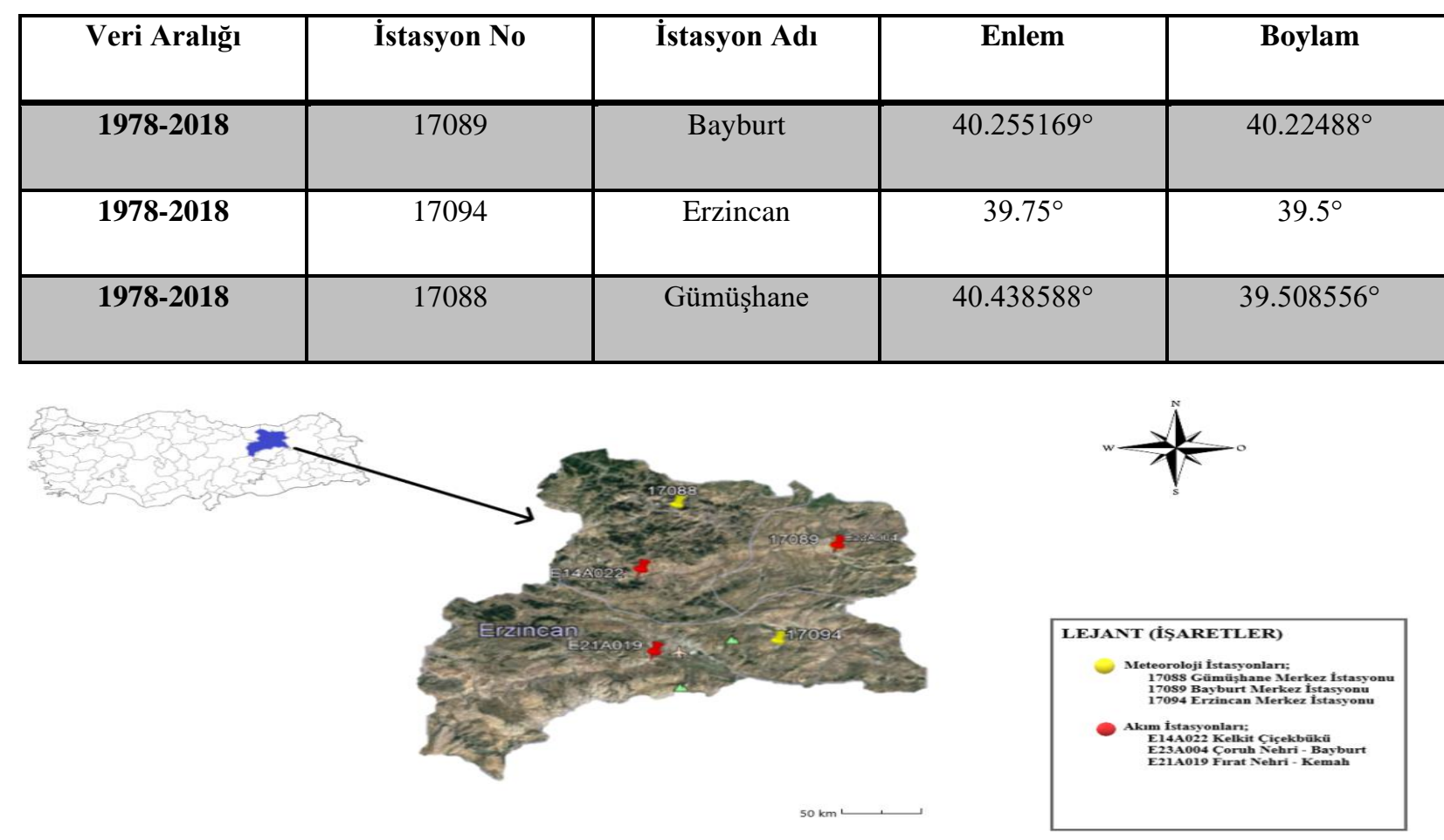

Şekil 2.1 Çalışma Alanı 


\section{Materyal ve Metod}

Çalışma Türkiye'nin Doğu Karadeniz bölgesine ve Doğu Anadolu bölgesine ait 3 ayrı istasyonda (Gümüşhane, Bayburt, Erzincan) gerçekleşmiştir. İklimsel olarak bu üç ili değerlendirecek olursak; Bayburt, Doğu Karadeniz ile Doğu Anadolu bölgelerinin iklimleri arasında bir geçiş sürmektedir. $\mathrm{Bu}$ sebepten yazları sıcak ve kurak, kışları ise soğuk ve yağmurlu geçmektedir. Kış ve yaz aylarını temsilen ocak ve temmuz aylarını seçecek olursak; ocak ayı ortalama sıcaklığ $1-5,9^{\circ}$, Temmuz ay1 ortalama sıcaklığ1 ise $19,1^{\circ}$ dir. Gümüşhane, Doğu Karadeniz bölgesine yakın kısımlar nemli ve 1lık geçerken Doğu Anadolu bölgesine yakın bölgeler kışları soğuk; yazları ise kurak ve sıcak geçer. Ocak ayı ortalama sıcaklığı $-1,6^{\circ}$ iken temmuz ayı ortalama sicaklığ $20,3^{\circ}$ dir. Erzincan'da ise sert karasal iklim hüküm sürer. Yazları kurak ve sıcak kışları iste soğuk ve yağışlı geçer. Ocak ayı ortalama sicaklığ $-2,4^{\circ}$, Temmuz ayı ortalama sıcaklığ 1 ise $24^{\circ}$, dir.

\subsection{Trend analizi}

Trend; herhangi bir bağımsız değişkenin gözlemlenen süre içindeki gösterdiği eğilim olarak tanımlanır. (Soydan vd., 2016) (Tuna vd. , 2009) Bir serinin trendinin belirlenmesi için kullanılan yöntemler, serinin bir dağılıma bağlı olup olmamasına göre; parametrik ve parametrik olmayan yöntemler olmak üzere iki başlık altına toplanmıştır.(Helsel and Hirsch, 1992; Kahya ve Kalayc1,2004). Mann-Kendall, Mann-Kendall sira korelasyon testi, Şen testi parametrik olmayan yöntemlerdir. (Tabari vd., 2011) Spearman Rho ise doğrusal trend varlığını belirleme de kullanılan bir testtir (Karakuş, 2017).
Kullanılan testlerde, parametrik olmayan yöntemlerin parametrik yöntemlere göre daha doğru sonuç verdiği bilinmektedir. (C1ğızoğlu vd. ,2004; Bari vd, 2016)

\subsubsection{Mann-Kendall testi}

Parametrik olmayan Mann-Kendall testi data dağılımından bağımsızdır. Bu yönteme göre $H_{\circ}$ hipotezi trendin olmadığ 1 varsayımı üzerine kurulur. Testin istatistiği;

$\mathrm{S}=\sum_{k=1 j}^{n-1} \sum_{k+1}^{n} \operatorname{sgn}(x j-x k)$

$\operatorname{Sgn}(x)=\left\{\begin{array}{c}+1, x>0 \\ 0, x=0 \\ -1, x<0\end{array}\right.$

Şeklinde hesaplanır. Formüldeki xj, xk ve n sırası ile j ve k yıllarında gözlemlenen değerleri, $\mathrm{n}$ ise toplam yıl sayısını ifade etmektedir. Eğer toplam yıl sayısı 10 yılı aşarsa $(\mathrm{n}>10)$ bir sonraki adımlar izlenecektir.

$\mu_{\mathrm{s}=0} \quad$ ve $\quad \sigma_{\mathrm{s}=} \sqrt{n(n-1)(2 n+5) / 18}$

$\mathrm{Z}=\left\{\begin{array}{l}\frac{(s-1)}{\sqrt{\operatorname{var}(s)}} s>1 \\ 0 s=0 \\ \frac{(s+1)}{\sqrt{\operatorname{var}(s)}} s<1\end{array}\right.$

Şekilde tanımlanan $Z$ istatistiğinin dağılımı standart normal dağılımdır. $Z$ değeri $\alpha$ önem derecesine karş1lık gelen $Z / 2$ değerinden küçük ise sıfır hipotezi kabul edilmekte ve incelenen zaman serisinde eğilim olmadığını; büyükse eğilim olduğunu ve s değeri pozitif ise artan yönde; negatif ise azalan yönde olduğu sonucuna varılmaktadır. (Kişi ve Ay, 2014) 


\subsubsection{Sperman Rho testi}

Doğrusal trendin var olup olmadığının araştırılmasında kullanılan basit ve hızlı bir yöntemdir. Sperman Rho testinde amaç iki gözlem serisi arasında doğrusal ilişkinin varlığını araştırmaktır. Sperman Rho testi istatistiği $r_{s}$ bağlantısı ile hesaplanır:

$\mathrm{r}_{\mathrm{s}=1}-6 \frac{\left\lfloor\sum_{i=1}^{n}(R(x i-\mathrm{i} 2))\right\rfloor}{(\mathrm{n} 3-\mathrm{n})}$

Eğer toplam yıl sayısı 30 yılı aşarsa ( $>30)$ bir sonraki adım izlenerek $\mathrm{Z}$ değeri hesaplanır.

$\mathrm{Z}=\mathrm{r}_{\mathrm{s}} \sqrt{n-1}$

$Z$ değeri $\alpha$ önem derecesin göre $Z / 2$ değerinden büyükse sıfir hipotezi reddedilerek belirli bir trendin olduğu, $r_{s}$ değeri pozitif ise artan yönde, negatif ise azalan yönde eğilim olduğunu göstermektedir.

\subsection{3.Şen trend eğilim metodu}

Şen (2012) tarafindan geliştirilen parametrik olmayan bir testtir. Şen Eğilim Metodu koordinat sistemi üzerinde çalışma yapılan bir testtir. İlk olarak zamanlar küçükten büyüğe doğru sıralanır. Zaman serisinin başlangıcından orta noktasına kadar olan zaman aralıkları ve asıl olarak 'sırası ile zaman aralıklarına ait veriler' $x$ eksenine, orta noktadan son noktaya kadar olan zaman serileri ve verileri de y eksenine yerleştirilir. Son olarak 0'dan $45^{\circ}$ lik bir açı ile çizgi geçirilir. İşaretlenen veriler bu çizginin üzerinde kalıyor ise trend pozitif, altında kalıyor ise trend negatiftir.

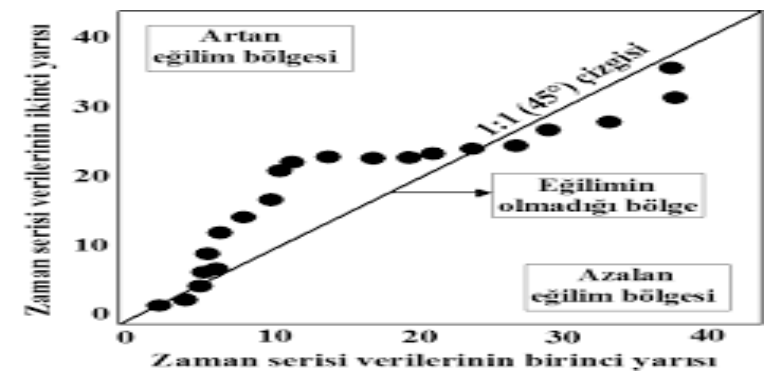

Şekil 3.1 Şen Eğilim Metodu Grafiği

\section{Bulgular}

Şen testi, Spearman's Rho, Mann-Kendall ve Mevsimsel Mann-Kendall Erzincan, Gümüşhane, Bayburt illerinin son kırk yıllık yağış verilerine uygulanmıştır. Mann - Kendall testi sonuçları \%95 güven aralığında test edilmiştir. Testlerde Anlamlılık düzeyi \%5 seçilmiştir.

\section{1 Şen trend testi sonuçları}

Şen testi analizi sonucunda Erzincan'da yağış verilerinin çoğunluğu 1:1 çizgisi yakınında toplanmıştır. Verilerin az bir kısmı ise azalan eğilim bölgesindedir (Şekil 4.1.1). Bu durum, son kırk y1llık yağış verilerinden anlaşılacağı gibi belirgin bir eğilim olmadığını göstermektedir. (Tekkanat, 2017) 


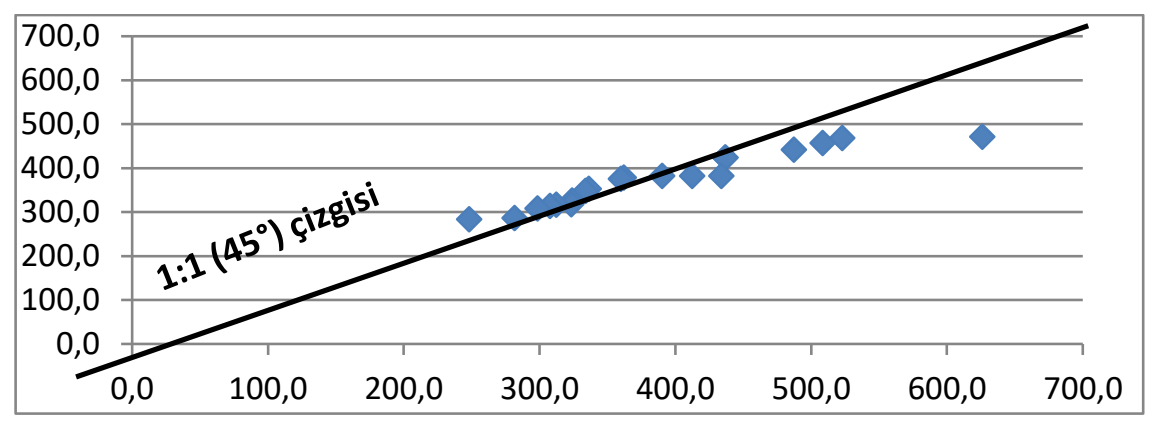

Şekil 4.1.1 Erzincan Şen Trend Testi Analiz Grafiği

Şen testine göre Gümüşhane'de veriler 1:1 çizgisinin yakılarında toplanmıştır (Şekil
4.1.2). Son k1rk y1llık verilere dayanarak önemli bir eğilim görülmemektedir.

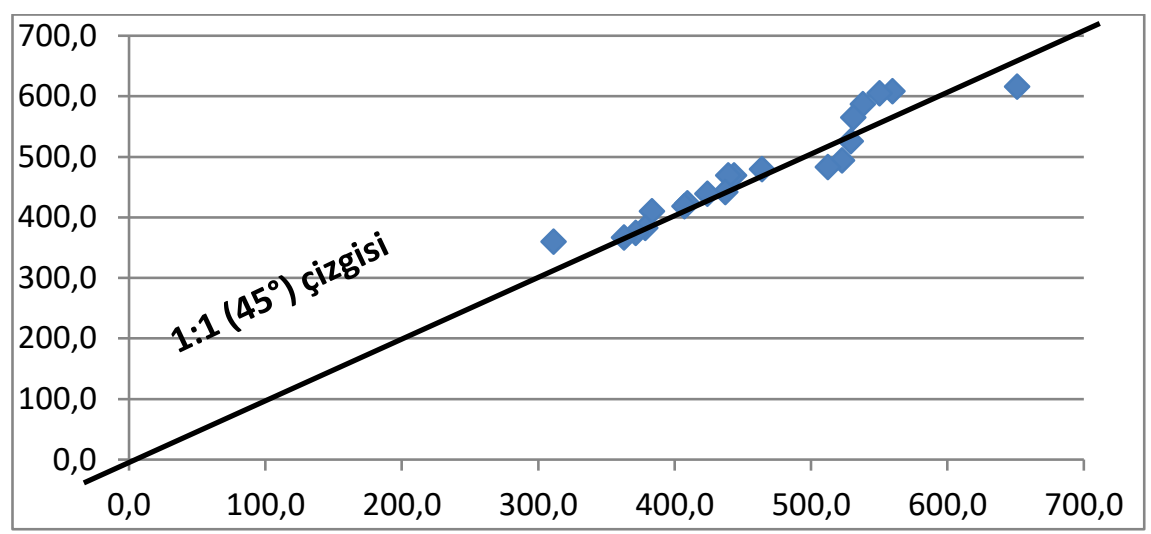

Şekil 4.1.2 Gümüşhane Şen Trend Testi Analiz Grafiği

Bayburt'un son kırk yıllık yağış verilerinin Şen testine göre verilerin çoğunluğu artan eğilim bölgesindedir. Az bir kısmı ise azalan eğilim bölgesindedir. (Şekil 4.1.3) Bu duruma göre Bayburt'ta artan bir eğilim vardir.

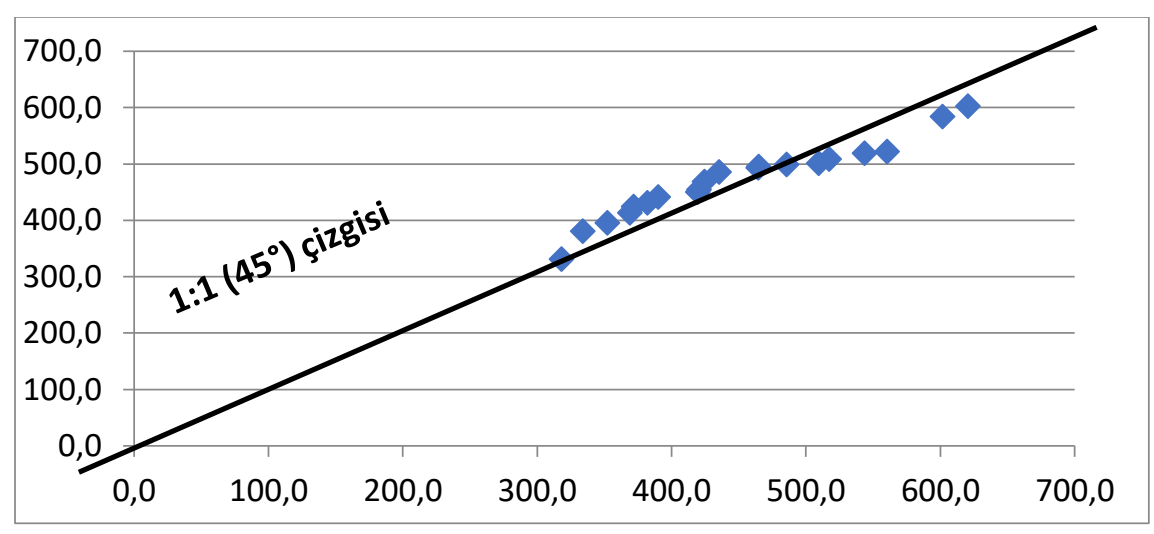

Şekil 4.1.3 Bayburt Şen Trend Testi Analiz Grafiği 


\subsection{Mann-Kendall trend testi sonuçları}

Mann-Kendall testi analizi sonucunda Erzincan istasyonunda Temmuz, Ağustos aylarındaki yağış verilerinde azalan eğilim göstermiştir. Diğer aylarda ise eğilim olmadığ1 görülmektedir (Tablo 4.2.1).

Tablo 4.2.1 Erzincan Mann-Kendall testi Sonuçları

\begin{tabular}{|c|c|c|c|c|c|}
\cline { 2 - 6 } & \multicolumn{3}{c|}{} & \multicolumn{4}{c|}{ Mann-Kendall } \\
\cline { 2 - 6 } & VAR(S) & $\mathrm{S}$ & $\mathrm{Zr}$ & \multicolumn{2}{c|}{ YORUM } \\
\hline Ocak & 7925.667 & 15.000 & 0.157 & TREND YOK & - \\
\hline Şubat & 7925.667 & -53.000 & -0.584 & TREND YOK & - \\
\hline Mart & 7925.667 & 171.000 & 1.910 & TREND YOK & - \\
\hline Nisan & 7925.667 & 31.000 & 0.337 & TREND YOK & - \\
\hline May1s & 7925.667 & 63.000 & 0.696 & TREND YOK & - \\
\hline Haziran & 7925.667 & -83.000 & -0.921 & TREND YOK & - \\
\hline Temmuz & 1830.500 & -281.000 & -6.544 & TREND VAR & AZALIŞ TRENDI \\
\hline Ağustos & 5619.667 & -188.000 & -2.495 & TREND VAR & AZALIŞ TRENDI \\
\hline Eylül & 5625.667 & -102.000 & -1.347 & TREND YOK & - \\
\hline Ekim & 7926.667 & -70.000 & -0.775 & TREND YOK & - \\
\hline Kasım & 6799.167 & -51.000 & -0.606 & TREND YOK & - \\
\hline Aralık & 6799.167 & 13.000 & 0.146 & TREND YOK & - \\
\hline Y1llık & 7925.667 & 15.000 & 0.157 & TREND YOK & - \\
\hline
\end{tabular}

Gümüșhane istasyonuna uygulanan MannKendall testi sonucunda Mart ayında artan eğilim, Ağustos ayında azalan eğilim göstermiștir. Diğer aylarda önemli bir eğilim olmadı̆̆ 4.2.2) 
Tablo 4.2.2 Gümüşhane Mann- Kendall testi Sonuçları

\begin{tabular}{|c|c|c|c|c|c|}
\hline & \multicolumn{5}{|c|}{ Mann-Kendall } \\
\hline & VAR(S) & $\mathrm{S}$ & $\mathrm{Zr}$ & \multicolumn{2}{|c|}{ YORUM } \\
\hline Ocak & 7924.667 & 10.000 & 0.101 & TREND YOK & - \\
\hline Şubat & 7925.667 & -33.000 & -0.359 & TREND YOK & - \\
\hline Mart & 7925.667 & 189.000 & 2.112 & TREND VAR & ARTIŞ TRENDİ \\
\hline Nisan & 7925.667 & -15.000 & -0.157 & TREND YOK & - \\
\hline Mayıs & 7925.667 & 15.000 & 0.157 & TREND YOK & - \\
\hline Haziran & 7926.667 & 50.000 & 0.550 & TREND YOK & - \\
\hline Temmuz & 5625.667 & -87.000 & -1.147 & TREND YOK & - \\
\hline Ağustos & 3140.000 & -198.000 & -3.516 & TREND VAR & AZALIŞ TRENDİ \\
\hline Eylül & 7926.667 & 104.000 & 1.157 & TREND YOK & - \\
\hline Ekim & 7925.667 & 53.000 & 0.584 & TREND YOK & - \\
\hline Kasım & 6797.167 & -11.000 & -0.121 & TREND YOK & - \\
\hline Aralık & 6797.167 & -43.000 & -0.509 & TREND YOK & - \\
\hline Yillık & 7926.667 & 18.000 & 0.191 & TREND YOK & - \\
\hline
\end{tabular}

Bayburt istasyonunda Mann- önemli bir eğilim görülmemektedir (Tablo Kendall testi sonuçlarına göre Ağustos 4.). ayında azalan bir eğilim, diğer aylarda ise

Tablo 4.2.3 Bayburt Mann-Kendall testi Sonuçları

\begin{tabular}{|c|c|c|c|c|c|}
\cline { 2 - 6 } \multicolumn{1}{c|}{} & \multicolumn{5}{c|}{ Mann-Kendall } \\
\cline { 2 - 6 } \multicolumn{1}{c|}{ Ocak } & 7924.667 & 102.000 & 1.135 & TREND YOK & - \\
\hline Şubat & 7924.667 & 10.000 & 0.101 & TREND YOK & - \\
\hline Mart & 7924.667 & 158.000 & 1.764 & TREND YOK & - \\
\hline Nisan & 7926.667 & 80.000 & 0.887 & TREND YOK & - \\
\hline Mayıs & 7924.667 & 112.000 & 1.247 & TREND YOK & - \\
\hline Haziran & 7925.667 & -59.000 & -0.651 & TREND YOK & - \\
\hline Temmuz & 7924.667 & 110.000 & 1.224 & TREND YOK & - \\
\hline Ağustos & 3140.000 & -393.000 & -6.996 & TREND VAR & AZALIŞ TRENDI \\
\hline Eylül & 6799.167 & -40.000 & -0.473 & TREND YOK & - \\
\hline Ekim & 7925.667 & 21.000 & 0.225 & TREND YOK & - \\
\hline Kasım & 6797.167 & -103.000 & -1.237 & TREND YOK & - \\
\hline Aralık & 6798.167 & -14.000 & -0.158 & TREND YOK & - \\
\hline Y1llık & 7926.667 & 118.000 & 1.314 & TREND YOK & - \\
\hline
\end{tabular}


Mevsimsel Mann-Kendall testi sonuçlarına göre Erzincan istasyonundaki yağış verilerinin yaz döneminde azalan eğilimde olduğu görülmektedir. Diğer mevsimlerde ise önemli bir eğilim olmadı̆̆ görülmektedir. (Tablo 4.2.4)

Tablo 4.2.4. Erzincan Mevsimsel Mann-Kendall testi sonuçları

\begin{tabular}{|c|c|c|c|c|c|c|}
\hline & \multicolumn{5}{|c|}{ Mevsimsel Kendall } \\
\hline & & VAR(S') & $\mathrm{S}^{\prime}$ & $\mathrm{Zr}$ & & ORUM \\
\hline 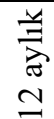 & Toplam dönem & 82154.833 & -535.000 & -1.863 & $\begin{array}{c}\text { TREND } \\
\text { YOK }\end{array}$ & - \\
\hline \multirow{4}{*}{ 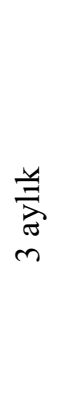 } & $\mathrm{K}_{1}$ ş & 22650.500 & -25.000 & -0.159 & $\begin{array}{c}\text { TREND } \\
\text { YOK }\end{array}$ & - \\
\hline & İlkbahar & 23777.000 & 265.000 & 1.712 & $\begin{array}{c}\text { TREND } \\
\text { YOK }\end{array}$ & - \\
\hline & Yaz & 15375.833 & -552.000 & -4.444 & TREND VAR & AZALIŞ TRENDİ \\
\hline & Sonbahar & 20351.500 & -223.000 & -1.556 & $\begin{array}{c}\text { TREND } \\
\text { YOK }\end{array}$ & - \\
\hline
\end{tabular}

Gümüşhane istasyonunda Mevsimsel önemli bir eğilim olmadığı görülmektedir Mann-Kendall testi sonucunda yağışlarda

(Tablo 4.2.5).

Tablo 4.2.5 Gümüşhane Mevsimsel Mann-Kendall testi Sonuçları

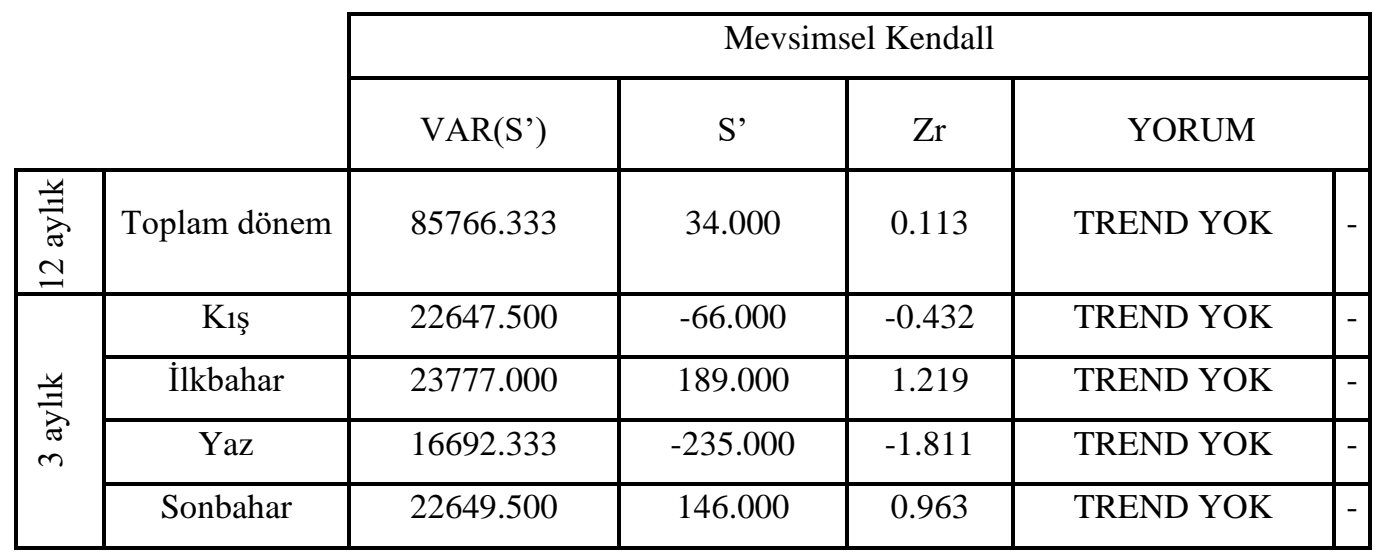

Bayburt istasyonunda ise döneminde azalan eğilim göstermiştir Mevsimsel Mann-Kendall testi sonuçlarına (Tablo 4.2.6). göre ilkbahar döneminde artan, yaz 
Tablo 4.2.6 Bayburt Mevsimsel Mann-Kendall testi Sonuçları

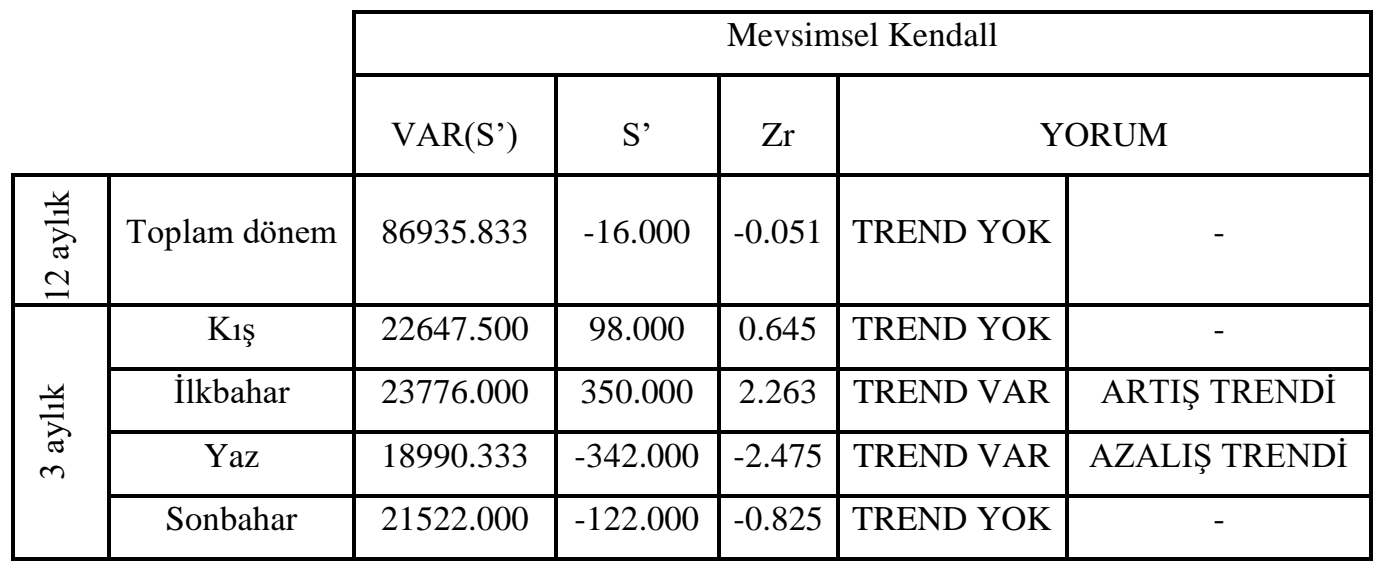

\subsection{Spearman's Rho testi sonuçları}

Spearman's Rho testi sonuçlarına göre Erzincan istasyonundaki yağışlarda
Temmuz ayında artan eğilim görülmektedir. Diğer aylarda ise yağışlarda önemli bir eğilim olmadığı görülmektedir (Tablo 4.3.1).

Tablo 4.3.1 Erzincan Spearman’s Rho testi Sonuçları

\begin{tabular}{|c|c|c|c|c|c|}
\hline \multirow{3}{*}{ Ocak } & \multicolumn{5}{|c|}{ Spearman's Rho } \\
\hline & \multirow{2}{*}{$\frac{\Sigma\left(\mathrm{M}_{\mathrm{i}-\mathrm{i}}\right)^{2}}{11234.500}$} & \multirow{2}{*}{$\frac{\mathrm{r}_{\mathrm{s}}}{0.021}$} & \multirow{2}{*}{$\frac{\mathrm{Iz}_{\mathrm{s}} \mathrm{I}}{0.135}$} & \multicolumn{2}{|c|}{ YORUM } \\
\hline & & & & TREND YOK & - \\
\hline Şubat & 12582.500 & -0.096 & 0.607 & TREND YOK & - \\
\hline Mart & 8050.500 & 0.299 & 1.889 & TREND YOK & - \\
\hline Nisan & 10990.500 & 0.043 & 0.270 & TREND YOK & - \\
\hline Mayıs & 10216.500 & 0.110 & 0.696 & TREND YOK & - \\
\hline Haziran & 12921.500 & -0.126 & 0.794 & TREND YOK & - \\
\hline Temmuz & 5730.000 & 0.501 & 3.168 & TREND VAR & ARTIŞ TRENDI \\
\hline Ağustos & 9938.500 & 0.134 & 0.849 & TREND YOK & - \\
\hline Eylül & 8350.500 & 0.273 & 1.724 & TREND YOK & - \\
\hline Ekim & 13004.000 & -0.133 & 0.840 & TREND YOK & - \\
\hline Kasım & 12558.000 & -0.094 & 0.594 & TREND YOK & - \\
\hline Aralık & 11274.000 & 0.018 & 0.113 & TREND YOK & - \\
\hline Y1ll1k & 11095.500 & 0.033 & 0.212 & TREND YOK & - \\
\hline
\end{tabular}

Spearman's Rho testi Gümüşhane istasyonunda yağış da Mart ayında artan eğilim görülmektedir. Diğer aylarda ise yağışda önemli bir eğilim olmadığ görülmektedir (Tablo 4.3.1). 
Tablo 4.3.1 Gümüşhane Spearman's Rho testi Sonuçları

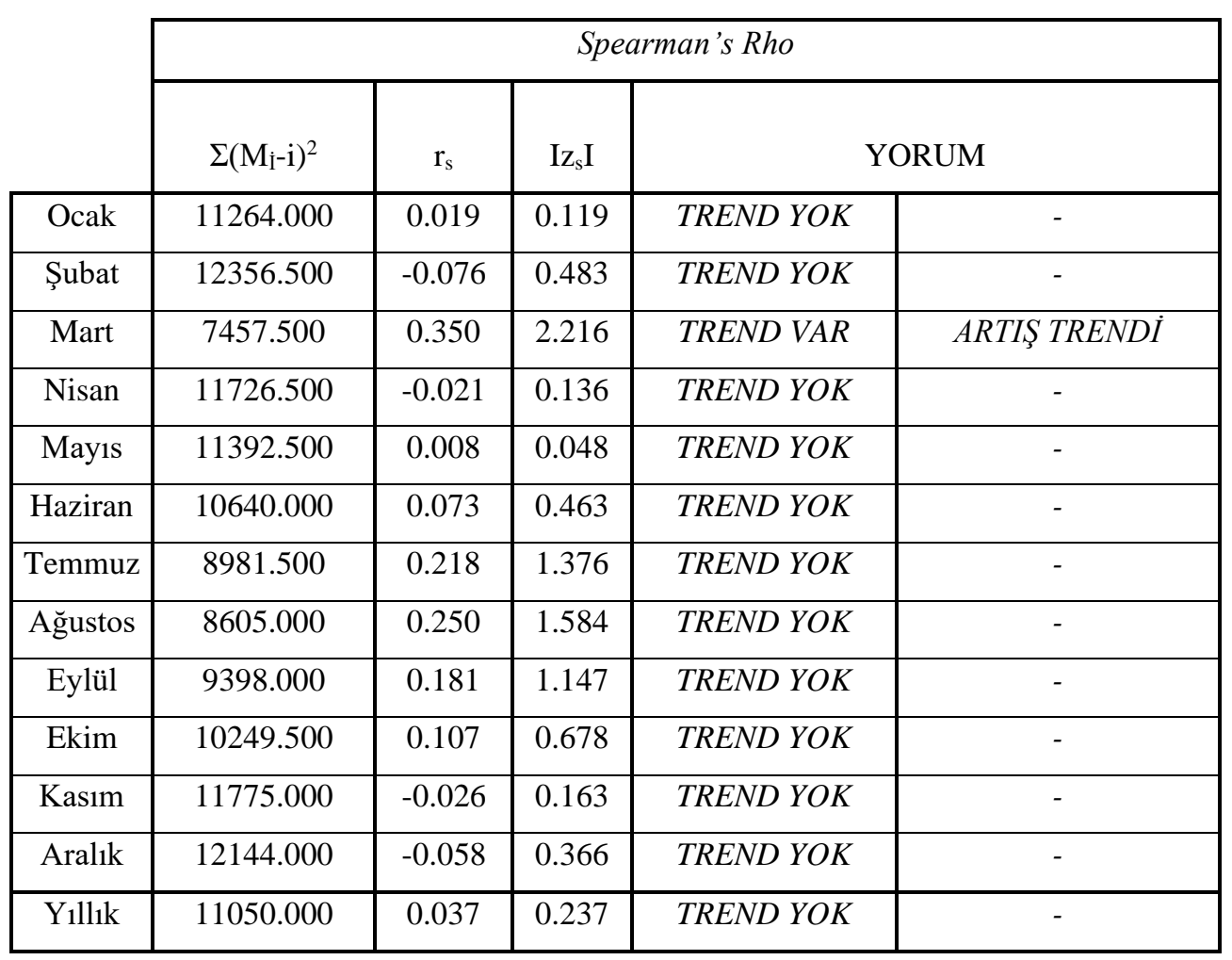

Bayburt istasyonu yağış verilerine göre Spearman's Rho testi sonuçlarında Ağustos ayında artan eğilim görülmektedir.
Diğer aylarda ise yağışta önemli bir eğilim olmadığı görülmektedir (Tablo 4.3.2).

Tablo 4.3.2 Bayburt Spearman's Rho testi Sonuçları

\begin{tabular}{|c|c|c|c|c|c|}
\hline \multirow[b]{3}{*}{ Ocak } & \multicolumn{5}{|c|}{ Spearman's Rho } \\
\hline & $\Sigma\left(\mathrm{M}_{\mathrm{i}-\mathrm{i}}\right)^{2}$ & $\mathrm{r}_{\mathrm{s}}$ & $\mathrm{Iz}_{\mathrm{s}} \mathrm{I}$ & \multicolumn{2}{|c|}{ YORUM } \\
\hline & 9342.000 & 0.186 & 1.178 & TREND YOK & - \\
\hline Şubat & 11202.000 & 0.024 & 0.153 & TREND YOK & - \\
\hline Mart & 8075.000 & 0.297 & 1.876 & TREND YOK & - \\
\hline Nisan & 10120.000 & 0.118 & 0.749 & TREND YOK & - \\
\hline Mayıs & 9206.000 & 0.198 & 1.253 & TREND YOK & - \\
\hline Haziran & 12553.500 & -0.094 & 0.591 & TREND YOK & - \\
\hline Temmuz & 8970.000 & 0.219 & 1.383 & TREND YOK & - \\
\hline Ağustos & 7785.000 & 0.322 & 2.036 & TREND VAR & ARTIŞ TRENDI \\
\hline Eylül & 10070.000 & 0.123 & 0.777 & TREND YOK & - \\
\hline Ekim & 10692.500 & 0.069 & 0.434 & TREND YOK & - \\
\hline Kasım & 13503.000 & -0.176 & 1.115 & TREND YOK & - \\
\hline Aralık & 11340.500 & 0.012 & 0.077 & TREND YOK & - \\
\hline Y1llik & 8820.000 & 0.232 & 1.465 & TREND YOK & - \\
\hline
\end{tabular}




\section{Sonuç}

$\mathrm{Bu}$ çalışmada Erzincan, Gümüşhane, Bayburt illerine ait gözlem istasyonlarının 1978-2010 yıllarındaki aylık yağış verilerinin trend analizi yapılmıştır. Trend analizinde Sen, Mann-Kendall, Mevsimsel Mann-Kendall ,Spearman's Rho gibi metotlar kullanılmıştır. Çalışma sonucunda, Erzincan, Gümüşhane, Bayburt illerinde yağışlarda yıl geneline yansıyan belirgin azalmalar veya artışlar tespit edilmemiştir. Fakat Erzincan, Gümüşhane ilinin Temmuz ayında, Bayburt ilinin ise Ağustos ayında yağışlarda azalan trend tespit edilmiştir. Yaz aylarındaki azalan trendin yanı sıra kış mevsiminde Mart ayında gözlenen artış eğilimi bize iklim değişikliğinin etkileriyle ilgili fikir vermektedir. Yaz aylarında kuraklık anlamında iklim değişikliği etkisiyle daha da çok baskı hissedebileceğimiz anlaşılmaktadır. Kış aylarında olası artış trendi ise bu aylarda yaşanabilecek ekstrem doğa olaylarının daha da artabileceğini göstermektedir. (Yerdelen, 2013)

Sonuç olarak bu çalışmada, üç ilin son kırk yıllık yağış verilerini ele alarak gelecekteki eğilimlerin doğru bir şekilde saptanması ve ileride iklim değişikliğinden korunabilmek, çevresel problemlerin saptanarak bu problemlere karşı çözümler üretebilmek; kuraklık ve taşkın gibi ekstrem olayların yaratabileceği baskının daha da artabileceğini ön görmek ve gerekli önlemlerin alınması açısından önemlidir. (Saplığlu ve Çoban ,2013)

\section{Kaynak}

Adarsh S. ve Reddy J. (2013) 'Trend analysis of rainfall in four meteorological subdivisions of southern India using nonparametric methods and discrete wavelet transforms', International Journal Of Climatology,(35-6),1107-1124.

Altın, B.R., Barak, B., Altın, B.N. (2012) 'Change in Precipitation and Temperature Amounts over Three Decades in Central Anatolia, Turkey', Atmospheric and Climate Sciences, (2)107-125.

Ay, M. Ve Kişi, Ö. (2017) 'Kızılırmak Nehrinde Bazı İstasyonlardaki Akımların Trend Analizi', IMO Teknik Dergi, 77797794, Yaz1 573.

Aydın F. Ve Topaloğlu F. (2010) 'Türekiye Buharlaşma Verilerinin Gidiș Analizi', Ç.Ü.Fen Bilimleri Enstitüsü, (22), 173-184.

Bacanlı, Ü. G. Ve Tanrikulu A. (2017) 'Ege Bölgesinde Buharlaşma Verilerinin Trend Analizi', AKÜ FEMÜBID , 980-987.

Bahadır M. (2011) 'Acıgöl Havzası'nda yağışın trend analizi ve haritalanması' Türk Coğrafya Dergisi', (57).

Bari H. S. ,Rahman M. T. ,Hoque A. M. ,Hussain M. M. (2016) 'Analiysis of Seasonal and Annual Rainfall Trends in the Northhern region of Bangladesh' Atmosperiv Research, (176-177), 148-158.

Bayazıt, M. Ve Cığızoğlu H. K. Ve Önöz B. (2002) 'Türkiye Akarsularında Trend Analizi', TMH, 420-421-422, 4-5-6.

C1ğızoğlu H. K. Ve Bayazıt M. Ve Önsöz B. (2004) 'Trends in the Maximum, Mean, and Low Flows of Turkish Rivers', Journal of Hydrometeorology, 280-290.

Gönençil B. ve İçel G. ( 2010) ‘Türkiye'nin Doğu Akdeniz kıyılarında y1llık toplam yağışlarda görülen değişimler (19752006)', Türk Coğrafya Dergisi, (55), 1-12.

Helsen D. Ve Hirsch R. (1992) 'An Assessment of Trends of Monthly Contributions to Seasonal Rainfall in South-Eastern Zimbabwe', American Journal of Climate Change , (3-1).

Kahya E. Ve Kalaycı S. (2004) 'Trend Analysis Of Streamflow in Turkey', Journal of Hydrology, 289, 128-144. 
Karakuş C. B. (2017) 'Trend Analysis Methods for Hydro-Meteorological Parameters', International Journal of Scientific and Technological Research, 2232.

Karpouzos, D., Kavalieratou, S., Babajimopoulos, C. (2010) 'Trend Analysis of Precipitation Data in Pieria Region (Greece)', European Water Publications, (30), 31-40.

Kişi Ö. Ve Ay M. (2014) 'Comprasion of Mann-Kendall and innovative trend method for water quality parameters of the Kizılırmak River, Turkey', Journal of Hidrology, 513, 362-375.

Mekis, E., Vincent L. A. (2011) 'An Overview of the Second Generation Adjusted Daily Precipitation Dataset for Trend Analysis in Canada' AthmosphereOcean, (49), 163-177.

Partal T. Ve Kahya E. (2006) 'Trend Analysis in Turkish Precipitation Data', Hydrological Processes , 13 .

Saplığlu K. Ve Çoban E. (2013) 'Karadeniz Yağış Serilerinin Trend Analizi', VII. Ulusal Hidroloji Kongresi, Süleyman Demirel Üniversitesi, Isparta, 500-512.

Soydan N. G. ,Gümüş V. ,Şimşek O. ,Gerger R. Ve Ağun B. (2016) 'Seyhan
Havzası aylık ortalama akım ve yağış verilerinin ternd analizi', Mühendislik Dergisi, 7, (2), 319-328.

Tabari H. ,Marofi S. ,Aeini A. ,Talaee H. P. ,Mohammadi K. (2011) 'Trend Analysis of Reference Evapotranspiration in the Western Half of Iran', Agricultural and Forest Meteorology, (151), 128-136.

Tekkanat, İ. S. (2017) 'Porsuk Çayı Üst Kesiminde Ortalama Akımların Şen Trend Metodu Kullanılarak Araştırılması', Coğrafi Bilimler Dergisi, CBD 15 (1), 49 57.

Tuna H. ,Malkoç F. ,Yılmaz Ö. (2009) 'Çoruh havzasında Spi ile Kuraklık Analizi ve Çevresel Etkileri' Doğu Karadeniz Bölgesi Hidroelektrik Enerji Potansiyeli ve Bunun Ülke Enerji Politakalırındaki Yeri, Trabzon, 114-129.

Yerdelen C. (2013) ' Susurluk Havzas1 Yıllık Akımların Trend Analizi ve Değişim Noktasının Araştırılması' DE Mühendislik Fakültesi Mühendislik Bilimleri Dergisi , (15), 77-87. 